\title{
Galerkin methods for fractional-stochastic systems
}

\author{
Mehmet Ali Akinlar ${ }^{1}$, Francisco Gómez $^{2}$, and Fatih Tasci ${ }^{3}$ \\ ${ }^{1}$ Bandirma Onyedi Eylul Universitesi \\ ${ }^{2}$ CENIDET \\ ${ }^{3}$ Yildiz Technical University
}

June 5, 2021

\begin{abstract}
Applicability of undetermined coefficients methods to several fractional-stochastic models is investigated. These models are mostly generated by fractional-order derivative operators and include a fractional white noise term. Application of a polynomial chaos algorithm to stochastic Lotka-Volterra and Benney systems are also investigated. Fractional-stochastic equations considered in this paper are totally original systems which may serve as models for many scientific and engineering phenomena. It is pointed out that Galerkin type methods employed in this paper may be efficiently applied to fractional-order systems having uncertainty or a noise term.
\end{abstract}

\section{Hosted file}

5FEM frc-stch.pdf available at https://authorea.com/users/302450/articles/524970-galerkinmethods-for-fractional-stochastic-systems 